\title{
Social Cognitive Intervention: Reducing Irritability and Impulsivity among Aggressive Adolescents
}

\author{
Dr. Parwinder Singh ${ }^{1}$ *
}

\section{ABSTRACT}

The study examines the effectiveness of Social Cognitive Intervention in reducing Irritability and Impulsivity among Aggressive Adolescents. The intervention was conceptualized using a Social Information Processing framework for understanding the development of aggressive behaviour. Social information processing theory emphasizes the active role of cognition in social adjustment. A five session Social-Cognitive Intervention was designed to train aggressive individuals not to infer hostile peer intent, to act non-impulsively and not to be irritated in negative social encounters and to provide various appropriate responses to such situations. By focusing on restructuring cognitions and changing social information processing pattern, it is assumed that changes in feelings of anger, irritability \& impulsivity would then follow which would further reduce aggression among individuals. 100 aggressive individuals were randomly assigned to experimental and control group. After 5 sessions of social cognitive intervention, all the aggressive individuals, from both experimental and control groups were administered Irritability and Impulsivity Questionnaires to assess the effectiveness of intervention. Experimental and control group were compared on both variables by applying a series of univariate ANOVAs. Same statistics were also applied to compare experimental and control group for males and females separately. Individuals in experimental group showed significant less Irritability and Impulsivity scores as compared to those in control group, thereby proving the effectiveness of social cognitive intervention. Implications for research and practice involving the treatment of aggressive adolescents are discussed.

Keywords: Social Cognitive Intervention, Hostile Attribution of Intent, Irritability, Impulsivity

Aggression has long been recognized as one of the most disruptive and pervasive childhood behavioral problems. Aggressive behavior tends to be highly stable from early childhood to adolescence and adulthood (e.g., Huesmann, Eron, Lefiowitz, \& Walder 1984; Olweus, 1979; Feshbach \& Fraczek, 1979, p. 2; Kazdin, 1987) and predicts a wide spectrum of adult adjustment problems (Kohlberg, Lacrosse, \& Ricks, 1972). For example, children who are highly aggressive

\footnotetext{
${ }^{1}$ Assistant Professor, Bebe Nanaki Guru Nanak Dev University College, Mithra, Kapurthala (Punjab)

*Responding Author

(c) 2016 I P Singh; licensee IJIP. This is an Open Access Research distributed under the terms of the Creative Commons Attribution License (http://creativecommons.org/licenses/by/2.0), which permits unrestricted use, distribution, and reproduction in any Medium, provided the original work is properly cited.
} 
in school settings, males in particular, are more likely than less aggressive children to engage in significantly higher rates of juvenile delinquency as they grow older (Loeber \& StouthamerLoeber, 1987). These boys are also more likely to experience poor overall school adjustment, peer rejection, greater than average rates of school drop out, and higher than average rates of referral for clinical mental health interventions (Kupersmidt \& Coie, 1990). A number of theoretical explanations have been proposed to account for the diversity and complexity of aggression and violence in humans. Among other factors, like frustration (Berkowitz, 1993), biased social information processing (Anderson \& Bushman, 2002), Narcissism (Baumeister, Bushman, \& Campbell, 2000) \& emotional susceptibility (Caprara et al., 1987), irritability and impulsivity (Barratt, 1994) have been associated with aggression (Anderson et al., 2004).

Previous studies for irritability and impulsivity show that, even when situations are relatively neutral, individuals who are high on impulsivity and irritability engage in higher levels of aggressive behavior than those who are low on the same (Anderson et al., 2004). According to Snaith and Taylor, 1985, Irritability is an unpleasant mood characterized by reduced control over temper that may result in irascible verbal or behavioural outbursts (Snaith and Taylor, 1985). Irritability is also defined as the "tendency to react controversially or rudely at the slightest provocation or disagreement" (Caprara, Cinanni, D'Imperio, Passerini, Renzi, \& Travaglia, 1985, p. 667). Irritability has been associated with a range and variety of verbal and physical behaviour. The definition of irritability includes being angrier, in general, and taking offense to the slightest provocation as well as the propensity to be offensive in the use of aggressive behavior (Caprara, 1982). Another important correlate of aggression is Impulsivity. Impulsivity is associated concurrently with verbal and physical aggression [Shapiro et al., 1988; Vigil-Colet and Codorniu Raga, 2004]. This is because impulsive individuals tend to respond quickly and without reflection (Barratt and Patton, 1983). Moreover, such individuals are unable to delay gratification when tolerance of delays produces a less risky outcome (Rachlin, 1974). This is the reason why impulsivity has been found to be associated with delinquency [White et al., 1994] and number of arrests and crimes committed [Babinski et al., 1999], In summary, the literature reveals a positive relation between irritability, impulsivity and aggressive behavior under both neutral and provoking conditions.

Impulsivity is associated with high levels of hostile behaviors (Atkins and Stoff, 1993) and hostile attribution bias (Schwartz et al., 1998). Nasby, Hayden, and dePaulo (1980) coined the term "hostile attribution bias" to describe the tendency of aggressive youth to attribute hostile intent to others. Hostile attribution of intent in turn are believed to cause aggressive behaviour, instigate more problematic social interaction, and thereby limit non-aggressive interactions that could provide opportunities to learn pro-social behaviour (Dodge, 1999; Weiss et al., 1992). Thus it is suggested that hostile attribution of intent may be a key element in the development and persistence of behavioural problems over time. The episodes of behavioural problems like irritability and impulsivity can be reduced (ultimately reducing the level of aggression) if appropriate training on how to use social information accurately is provided to aggressive individuals. 
In the present study, the above mentioned two important correlates of aggression, namely irritability and impulsivity was the target for change. A five session Social-Cognitive Intervention was designed specifically for the present research work with material and activities appropriate for the age group of 12-15 years. The primary goal of the intervention was to train aggressive individuals not to infer hostile peer intent, to act non-impulsively and not to be irritated in negative social encounters and to provide various appropriate responses to such situations. By focusing on restructuring cognitions and changing social information processing pattern, it was assumed that changes in feelings of anger, irritability \& impulsivity would follow which would further reduce aggression among individuals as both are found to be related (Caprara \& Renzi, 1981). A number of studies have demonstrated the effectiveness of intervention strategies and programs specifically designed to prevent or reduce anti-social behaviour by targeting social cognitive and social information processing skills linked to social behaviour (Gottfredson, 1997; Hughes \& Cavell, 1995; Larson, 1994,). Likewise, training in social problem solving is frequently a part of mental health treatment programs for aggressive and antisocial children (Kazdin, 1994).

\section{METHOD:}

\section{Selection of Subjects:}

Initially 300 individuals (150 males and 150 females) with the mean age of 13.60 years ( $\mathrm{SD}=1.03$ years) were randomly selected from four schools of Patiala and Chandigarh (Punjab, India). The subjects were administered Aggression Questionnaire (Buss \& Perry, 1992) and 100 individuals with equal number of males and females $(n=50)$ scoring high on Aggression were selected. Scores on Aggression Questionnaire (Buss \& Perry, 1992) were tabulated in descending order separately for males \& females. For both males and females, ranked score of aggression were divided into two halves i.e. upper 33\% \& lower 33\%, leaving middle $34 \%$ out for calculation. Participants in Upper 33\% half were considered high on aggression. From both groups, 50 aggressive males and 50 aggressive females were then finally selected for including in the study. These 100 individuals were then randomly assigned to experimental and control group. This assignment was done with the help of slips representing each aggressive individual. The total numbers of aggressive individuals for each school were divided into two halves by drawings those slips randomly and putting it in two blind boxes. After this, one of these boxes was assigned as experimental group and other one as control group. There were equal number of males and females in control group and experimental group. Demographic characteristics of sample used are given below in detail. 
Social Cognitive Intervention: Reducing Irritability and Impulsivity among Aggressive Adolescents

Table 1: Demographic characteristics of sample

\begin{tabular}{|l|l|l|l|l|}
\hline & $\begin{array}{l}\text { Gender } \\
\text { Specification }\end{array}$ & $\begin{array}{l}\text { Numbers of } \\
\text { individuals }\end{array}$ & $\begin{array}{l}\text { Mean Age(In } \\
\text { Years) }\end{array}$ & SD (In Years) \\
\hline Total Sample & & 100 & 13.38 & 0.91 \\
\hline & & & & \\
\hline & Males & 25 & 13.58 & 0.97 \\
\hline Control group & Females & 25 & 13.24 & 0.66 \\
\hline & Total & 50 & 13.41 & 0.84 \\
\hline & & & & \\
\hline & Males & 25 & 13.46 & 1.07 \\
\hline $\begin{array}{l}\text { Experimental } \\
\text { group }\end{array}$ & Females & 25 & 13.24 & 0.87 \\
\hline & Total & 50 & 13.35 & 0.98 \\
\hline
\end{tabular}

\section{Measures:}

Aggression (Buss and Perry, 1992):

The revised version of 'Buss \& Durkee Hostility Inventory' (Buss \& Durkee, 1957) i.e. Aggression Questionnaire (Buss \& Perry, 1992) was used to assess aggression. It consists of 29 items, distributed unequally among Anger ( 7 items- item number $1,9,12,18,19,23 \& 28$ ), Physical Aggression (9 items-item number 2, 5, 8, 11, 13, 16, 22, 25 \& 29), Hostility (8 itemsitem number 3, 7, 10, 15, 17, 20, 24 \& 26) \& Verbal Aggression (5 items- item number 4, 6, 14, 21 \& 27). It measures hostile aggression, because it contains items for aggressive behaviour and for angry/hostile feelings. For the total score, internal consistency (alpha) is .89 and 9-week testretest reliability is .80 (Buss \& Perry, 1992; Harris, 1997). Validity is supported by acceptable correlations with other self-report measures of aggression and with peer nominations of aggressive behaviour (Buss \& Perry, 1992; Harris, 1997).

Irritability (Caprara et al., 1985).

The scale contains 30 items along with a 6-point Likert-type scale for each item ranging from 5 (completely true for me) to 0 (completely false for me). Authors reported good reliability i.e. coefficient alpha for the scale is found to be .81, the split-half correlation is .90, and the testretest correlation is 83.2.

\section{Impulsivity (BIS-11, Patton et al., 1995).}

Impulsivity was measured with the help of Barratt Impulsiveness Scale (BIS-11, Patton et al., 1995). Barratt Impulsiveness Scale (BIS-11) consists of 30 statements of personal characteristics. Respondents are asked to indicate the extent to which the statements apply to them using a fourpoint scale ranging from rarely/never to always/almost always. Each is rated on a 1 rarely/never) to 4 (always/almost always) scale. The BIS-11 has been used with a variety of populations (e.g. Crean et al., 2000; Kirby et al., 1999) and has demonstrated good reliability and validity (Fossati 
et al., 2002; Patton et al., 1995). Patton et al. (1995) report internal consistency coefficients for the BIS-11 total score that range from 0.79 to 0.83 .

\section{Social Cognitive intervention:}

After assigning aggressive individuals into two groups, i.e. experimental group and control group, Participants in experimental group were given five session intervention. Detail of each session is as follows:

\section{Session I:}

First session consisted of general introduction in which purpose, procedure \& benefit of the program were discussed. Role of personality and specially role of cognitions in all kind of behaviour was also highlighted. ABC model of behaviour (Ellis, 1993) \& other exercises with effect of perception on behaviour as the main concern were discussed.

\section{Session II:}

In second session, aggression and its negative effect on us \& others were demonstrated. Role of cognitions in aggressive behaviour were linked with the help of some activities \& exercises.

\section{Session III:}

In third session, concept of ambiguous situation was defined \& possibility of negative ambiguous situation as an accidental one was also discussed. Role of uncontrolled and unintentional situational factors in negative social ambiguous situation was the main concern of the session. Significance of feelings in one's reaction to social stimuli was also elaborated.

\section{Session IV:}

Fourth session was basically related to our responses after attribution and what we should keep in mind while reacting to negative ambiguous social situation.

\section{Session V:}

In fifth session, other factors that predispose individual to misattribute intentions and behave aggressively were discussed. Hypothetical scenarios were used to practice all the steps that they learnt in previous sessions i.e. from negative encounter to appropriate response in which getting information about situation, attributing intent \& finally choosing appropriate responses were included.

The Intervention program was carried out in the school premises. The respective principals of different schools were made aware of the aims of the program and its usefulness for students. It was only after the consent of the school authorities that the program was conducted. There were 10-12 participants in each group as they were from different schools. Trained counselling Psychologist conducted these sessions. Each session was of 70 to 75 minutes duration. No student was absent during any session as sessions were planned according to students availability and convenience of the school. This whole exercise took around 40 days.

Participants were given some home assignment after each session to perform in which they had to note some observation and do some relaxation exercises for which they were trained briefly 
during each session. One follow-up session of general interaction with them was scheduled to get feedback which came out to be very satisfactory. Findings of the study are mentioned in following sections.

\section{Procedure:}

Aggressive individuals were randomly assigned to experimental and control group ( $\mathrm{n}=50)$ with the procedure mentioned above. The experimental group was given 5-session social cognitive intervention designed specifically to deal with hostile attribution of intent and thereby reducing aggression. To avoid unethical practice, control group was also given a sort of intervention in which neutral or unrelated issues were discussed like study habits, time management \& appropriate approach in career selection. After 5 sessions of social cognitive intervention, all the aggressive individuals, from both experimental and control groups were administered Irritability and Impulsivity Questionnaires to assess the effectiveness of intervention. Experimental and control group were compared on both variables by applying a series of univariate ANOVAs. Same statistics were also applied to compare experimental and control group for males and females separately. Finally results were interpreted and findings were discussed.

\section{RESULTS:}

Findings of the study are mentioned in the Tables and Figures given in Appendix 1.

Table 2 clearly indicates that social cognitive intervention was successfully used in the present experiment. Individuals in the experimental group received social cognitive intervention which had a significant effect on level of irritability and impulsivity. Subjects in the control group had a higher level of irritability $(M=95.26)$ than those in experimental group $(M=62.46)$ \& this difference came out to be highly significant $\{F(1,98)=117.5, \mathrm{p}<0.01\}$. Same trend has been observed for both males and females i.e. when compared separately both groups scored significant less scores on irritability. For impulsivity control group scored more $(\mathrm{M}=73.68)$ as compared to experimental group $(\mathrm{M}=61.10)$. The difference between both groups with less scores in experimental group has been found to be significant $\{F(1,98)=29.87, p<0.01)$. Although the difference between control group and experimental group on impulsivity was significant for both males and females, females were found to have more benefit from social cognitive intervention as the difference between control and experimental group was more for female group $\{F(1,98)=25.76, p<0.01)$ as compared to male group $\{F(1,98)=9.74, p<0.01)$. Summary of ANOVA for both irritability and impulsivity is presented in Table 3 . Findings of study have been graphically represented in Figure $1 \& 2$. Thus it can be stated here that restructuring of social cognitions and social information processing style of the subjects in the experimental group has significant effect on the level of their irritability and impulsivity of aggressive individuals. Reduction in irritability and impulsivity may further reduce the levels of aggression. 


\section{DISCUSSION:}

The main issue dealt with in the present experiment was, 'can social cognitive intervention lead to a change in the irritability and impulsivity level of aggressive individuals?' Though a lot of research has been done in the area of aggression and its correlates (Bandura, 2001; Baumeister, Bushman, \& Campbell, 2000; Barratt, 1994; Berkowitz, 1993), none, to our knowledge (in Indian setting) has used social cognitive intervention to reduce irritability and impulsivity.

Results clearly indicate that social cognitive intervention was successfully used in the present experiment. Individuals in the experimental group received social cognitive intervention which had a significant effect on level of irritability and impulsivity. Subjects in the control group had a higher level of irritability $\{\mathrm{F}(1,98)=117.5, \mathrm{p}<0.01\}$ and impulsivity $\{\mathrm{F}(1,98)=29.87, \mathrm{p}<0.01)$ than those in experimental group and these differences were found to be highly significant.

As discussed above, irritability and impulsivity are important correlates of aggressive behaviour. We used social cognitive intervention to reduce irritability and impulsivity hoping that this would reduce aggression. This does not mean that by simply reducing irritability, their aggression can be treated. The only fact that the finding of the present experiment provide is that social cognitive intervention can be successfully used to reduce irritability and impulsivity in aggressive individuals. Since irritability impulsivity \& aggression have been found to be associated (Caprara \& Renzi, 1981; Caprara, Barbaranelli, \& Comrey, 1992), change (in present case, reduction) in one can be expected to be related with change in other. Another important implication of the present findings is that social cognitive intervention has been especially useful in taking care of irritability of adolescents, as it was an adolescent sample \& in early adolescents, it has been reported that fluctuation in hormones are associated with greater irritability (Buchanan et al 1992), thus beside its correlation with aggression, irritability in itself is very crucial to handle so that various problems usually associated with adolescence can be avoided.

Another significant finding of the present research work was that the aggressive individuals in experimental group showed less impulsivity as compared to those on the control group. Since impulsive individual do not think of consequences before responding to the situation, they end up acting aggressively. Personality research characterizes impulsivity as the enduring tendency to act without thinking or to respond quickly to a given stimulus, without deliberation or evaluation of consequences [White et al., 1994]. This deficit in attention to future consequences is corrected at the response evaluation step of social information processing (SIP) model, which requires consideration of both immediate and long-term future consequences of an action or response that helps in reducing impulsivity. In the context of SIP patterns, a child who often acts without considering the unique elements of a particular social situation may be more likely to rely on their "default" way of processing and responding. When faced with a potentially conflictual situation in real life, children who are not impulsive are likely to consider the unique elements of the situation at hand and deliberate on the future consequences of their potential responses. However, impulsive children are less likely to integrate peripheral information and 
consider long-term future consequences of their actions in a particular situation, and by failing to do so; they may not recognize important differences between hypothetical and real responses. Furthermore, once an aggressive response has been put into action, non-impulsive children may be more able to process immediate feedback and alter their response. However, once the impulsive child has enacted a response, he/she may not possess the effortful control skills necessary to reevaluate or change a response once it has been enacted [Newman and Wallace, 1993]. In the present intervention, aggressive individuals were trained with help of social information processing model, to evaluate responses and their consequences and not to have predetermined mental set while responding in negative encounter and have non-impulsive and fresh appraisal of the situation. Such kinds of strategies have been proved to lower down the impulsiveness of aggressive individual.

The subjects in the experimental group were interviewed after the social cognitive intervention. They reported that the exercises that were a part of intervention helped them see things in a new perspective. It helped them relax, re-focus \& re-think on certain important issues of life. They felt changed. This kind of feedback can lead us to infer that social cognitive intervention has important role not only to reduce irritability, impulsivity \& aggression but other behaviour as well.

Separate analysis for the effect of intervention on males and females proved that such intervention is helpful in reducing irritability, impulsivity for both males and females.

The effective \& proper use of social cognitive intervention can have far reaching positive effects on an individual's life. Focusing cognitions \& targeting them for change can help an aggressive individual to see aggression provoking scenario from a new perspective with relaxed state of mind.

\section{LIMITATIONS:}

The findings however may not be generalized to individuals with different age group, culture \& background since the data was gathered from four public urban schools of two cities but it can work as very important guidelines for counsellors in different educational institutes. Thus it should be tested in diverse settings to enhance its external validity. Moreover, intervention should be tested by taking into consideration the other significant correlates of aggression and some behavioural measures of aggression can also be used.

\section{REFERENCES:}

Anderson, C. A., \& Bushman, B. J. (2002). Human aggression. Annual Review of Psychology, 53, 27-51.

Anderson, C. A., Carnagey, N. L., Flanagan, M., Benjamin, A. J., Eubanks, J., \& Valentine, J. C. (2004). Violent video games: specific effects of violent content on aggressive thoughts and behavior. Advances in Experimental Social Psychology, 36, 199-249.

Atkins M.S., Stoff D.M. (1993).Instrumental and hostile aggression in childhood disruptive behavior disorders. Journal of Abnormal Child Psychology; 21: 165-178. 
Babinski L.M., Hartsough C.S., Lambert N.M. (1999). Childhood conduct problems, hyperactivity-impulsivity, and inattention as predictors of adult criminal activity. Journal of Child Psychology and Psychiatry 40:347-355.

Bandura A. (2001). Social cognitive theory: an agentic perspective. Annuai Review of Psychology. 52:1-26

Barratt, E. S. (1994). Impulsiveness and aggression. In J. Monahan \& H. J. Steadman (Eds.), Violence and mental disorder: Developments in risk assessment (pp. 61-78). Chicago: University of Chicago Press.

Barratt, E. S. and Patton, J. (1983) 'Impulsivity: Cognitive, Behavioural and Psychophysiological Correlates’. In: Zuckerman, M. (ed.) Biological Bases of Sensation Seeking, Impulsivity and Anxiety. Hillsdale, N J: Lawrence Erlbaum Associates, pp. 77122.

Baumeister, R. F., Bushman, B. J., \& Campbell, K. (2000). Self-esteem,narcissism, and aggression: Does violence result from low self-esteem or from threatened egotism? Current Directions in Psychological Science, 9, 26-29.

Berkowitz, L. (1993). Aggression: Its causes, consequences, and control. New York: McGrawHill.

Buchanan C.M., Eccles J.S., Becker J.B. (1992). Are adolescents victims of raging hormones: evidence for activational effects of hormones on moods and behavior at adolescence? Psychology Bulletin, 111:62-107

Buss, A. H., \& Durkee, A. (1957). An inventory for assessing different kinds of hostility. Journal of Consulting Psychology, 21, 343-349.

Buss, A. H., \& Perry, M. (1992). The aggression questionnaire. Journal of Personality and Social Psychology, 63 (3), 452-459.

Caprara, G. V. (1982). A comparison of the frustration-aggression and emotional susceptibility hypotheses. Aggressive Behavior, 8, 234-236.

Caprara, G. V., \& Renzi, P. (1981). The frustration aggression hypothesis vs. irritability. Researches the Psychologie Sociale, 3, 75-80.

Caprara, G. V., Barbaranelli, C., \& Comrey, A. L. (1992). A Personological approach to the study of aggression. Personality and Individual Differences, 13, 77-84.

Caprara, G. V., Cinanni, V., D’Imperio, G., Passerini, S., Renzi, P., \& Travaglia, G. (1985). Indicators of impulsive aggression: Present status of research on irritability and emotional susceptibility scales. Personality and Individual Differences, 6, 665-674.

Caprara, G. V., Gargaro, T., Pastorelli, C., Prezza, M., Renzi, P., \& Zelli, A. (1987). Individual differences and measures of aggression in laboratory studies. Personality and Individual Differences, 8, 885-893.

Crean, J. P., de Wit, H., Richards, J. B. (2000). Reward discoutning as a measure of impulsive behavior in a psychiatric outpatient population. Experimental and Clinical Psychopharmacology 8 (2), 155-162.

Dodge, K. A. (1999). Development and prevention of chronic violence in children and adolescents. Colloquium at the University of Alabama - Birmingham, Birmingham, AL.. 
Ellis, A. (1993). Changing Rational Emotive Therapy (RET) to rational emotive behaviour therapy (REBT). Behaviour Therapist, 16, 257-258.

Feshbach, S., \& Fraczek, A. (1979). Changing aggression: The need and the approach. In S. Feshbach \& A. Fraczek (Eds.), Aggression and behavior change: Biological and social processes (pp. 1-5). New York: Praeger.

Fossati, A., Barratt, E., Acquarini, E., DiCeglie, A. (2002). Psychometric properties of an adolescent version of the Barratt Impulsiveness Scale-11 for a sample of Italian high school students. Perceptual and Motor Skills 95 (2), 621-635.

Gottfredson, D. C. (1997). School based crime prevention. In L. W. Sherman, D. C. Gottfredson, D. MacKenzie, J.Eck, P. Reuter, \& S. Bushway (Eds.), Preventing Crime: What works, works does not, what is promising: A report to the United States Congress. Washington, DC: Department of Justice.

Harris, J. A. (1997). A further evaluation of the aggression questionnaire: Issues of validity and reliability. Behavioural Research and Therapy, 35 (11), 1047-1053.

Huesmann, L. R., Eron, L. D., Lefkowitz, M. M., \& Walder, L. 0 . (1984). Stability of aggression over time and generations. Developmental Psychology, 20, 1120-1134.

Hughes, J. \& Cavell, T. A. (1995). Cognitive-affective approaches: Enhancing competence in aggressive children. In G. Cartledge \& J.F. Milburn (Eds), Teaching skills in children and youth. (pp. 199-236). Boston; Allyn \&Bacon.

Kazdin, A. (1987). Conduct disorders in childhood and adolescence. Newbury Park, CA: Sage.

Kazdin, A. E. (1994). Antisocial behavior and conduct disorder. In L. W. Craighead \& W. E. Craighead (Eds.), Cognitive and behavioral interventions: An empirical approach to mental health problems (pp. 267-299). Boston: Allyn \& Bacon.

Kirby, K. N., Petry, N. M., Bickel, W. K. (1999). Heroin addicts have higher discount rates for delayed rewards than non-drug-using controls. Journal of Experimental Psychology: General 128 (1), 78-87.

Kohlberg, L., Lacrosse, I., \&Ricks, D. (1972). The predictability of adult mental health from childhood behavior. In B. B. Wolman (Ed.), Manual of child psychopathology (pp. 12171284). New York: McGraw-Hill.

Kupersmidt, J. B., \& Coie, J. (1990). Preadolescent peer status, aggression, and school adjustment as predictors of externalizing problems in adolescence. Child Development, 61, 1350-1362.

Larson, J (1994). Violence prevention in the schools: A review of selected programs and procedures. School Psychology Review. 23, 151-164.

Loeber, R., \& Stouthamer-Loeber, M. (1987). Prediction. In H. Quay (Ed.), Handbook of juvenile delinquency. New York: Wiley.

Nasby, W., Hayden, B., \& DePaulo, B. M. (1980) Attributional bias among aggressive boys to interpret unambiguous social stimuli as displays of hostility. Journal of Abnormal Psychology, 89, 459- 468.

Newman J.P., Wallace J.F.(1993). Diverse pathways to deficient self-regulation: Implications for disinhibitory psychopathology in children. Clinical Psychology Review 13:699-720. 
Olweus, D. (1979). Stability of aggressive reaction patterns in males: A review. Psychological Bulletin, 86, 852-875.

Patton, J. H., Stanford, M. S., Barratt, E. S., (1995). Factor structure of the Barratt impulsiveness scale. Journal of Clinical Psychology 51 (6), 768-774.

Rachlin, H. (1974) 'Self-control'. Behaviorism 2: 94-107.

Schwartz D, Dodge K.A., Cole J.D., Hubbard J.A., Cillessen A.H.N., Lemeris E.A., Bateman H. (1998). Social-cognitive and behavioral correlates of aggression and victimization in boys’ play groups. Journal of Abnormal Child Psychology 1998; 26: 431-440.

Shapiro S.K., Quay H.C., Hogan A.E., Schwartz K.P. (1988). Response perseveration and delayed responding in under socialized aggressive conduct disorder. Journal of Abnormal Psychology 97: 371-373.

Snaith, R. P., and Taylor, C. M. (1985). Irritability: definition, assessment, and associated factors. British Journal of Psychiatry 147: 127- 136.

Vigil-Colet A., Codorniu-Raga M.J. (2004). Aggression and inhibition deficits, the role of functional and dysfunctional impulsivity. Personality and Individual Differences 37:1431-1440.

Weiss, B., Dodge, K. A., Bates, J. E., \& Pettit, G. S. (1992). Some consequences of early harsh discipline: Child aggression and a maladaptive social information processing style. Child Development, 63, 1321-1335

White, J. L., Moffitt, T. E., Caspi, A., Bartusch, D. J., Needles, D. J. and Stouthammer-Loeber, M. (1994). Measuring Impulsivity and Examining its Relationship to Delinquency'. Journal of Abnormal Psychology 103: 192-205.

\section{APPENDIX 1:}

Table 2, Means and Standard Deviations of Irritability and Impulsivity scores obtained by Males, Females and combined sample in control \& experimental Group along with F-ratios.

\begin{tabular}{|l|l|l|l|l|l|}
\hline \multicolumn{7}{|l|}{ Irritability scores } \\
\hline Groups & \multicolumn{4}{l|}{ Control group } & \multicolumn{2}{l|}{ Experimental group } & \\
\hline & Means & SD $^{\mathbf{a}}$ & Means & SD $^{\mathbf{a}}$ & F-ratio \\
\hline Combined Sample & 95.26 & 13.041 & 62.46 & 16.9624 & 117.502 \\
\hline Males & 95.32 & 14.25284 & 62.44 & 18.7796 & 48.62639 \\
\hline Females & 95.2 & 12.00347 & 62.48 & 15.32188 & 70.649 \\
\hline & Impulsivity scores & \multicolumn{4}{|l|}{} \\
\hline Groups & Control group & Experimental group & \\
\hline & Means & SD & Means & SD & F-ratio \\
\hline Combined Sample & 73.68 & 10.14 & 61.10 & 12.73 & $29.87^{*}$ \\
\hline Males & 74.36 & 11.57 & 62.40 & 15.28 & $9.74^{*}$ \\
\hline Females & 73.00 & 8.66 & 59.80 & 9.70 & $25.76^{*}$ \\
\hline
\end{tabular}

Note: Values are means scores of Irritability and Impulsivity a- Standard Deviation 
Social Cognitive Intervention: Reducing Irritability and Impulsivity among Aggressive Adolescents

Table 3, Summary of ANOVA for the Effect of Intervention (Experimental \& Control Group) on Irritability and impulsivity for combined sample.

\begin{tabular}{|l|l|l|l|l|l|l|l|l|}
\hline Variables & & SS Effect & $\begin{array}{l}\text { df } \\
\text { Effect }\end{array}$ & $\begin{array}{l}\text { MS } \\
\text { Effect }\end{array}$ & $\begin{array}{l}\text { SS } \\
\text { Error }\end{array}$ & $\begin{array}{l}\text { df } \\
\text { Error }\end{array}$ & $\begin{array}{l}\text { MS } \\
\text { Error }\end{array}$ & F \\
\hline \multirow{4}{*}{ Irritability } & $\begin{array}{l}\text { Combined } \\
\text { Sample }\end{array}$ & 26896.00 & 1 & 26896.00 & 22432.04 & 98 & 228.8984 & $117.50^{*}$ \\
\cline { 2 - 10 } & Males & 13513.68 & 1 & 13513.68 & 13339.60 & 48 & 277.91 & $48.63^{*}$ \\
\cline { 2 - 10 } & Females & 13382.48 & 1 & 13382.48 & 9092.24 & 48 & 189.42 & $70.65^{*}$ \\
\hline \multirow{3}{*}{ Impulsivity } & $\begin{array}{l}\text { Combined } \\
\text { Sample }\end{array}$ & 3956.41 & 1 & 3956.41 & 12981.38 & 98 & 132.4631 & $29.87^{*}$ \\
\cline { 2 - 10 } & Males & 1788.02 & 1 & 1788.02 & 8815.76 & 48 & 183.66 & $9.74^{*}$ \\
\cline { 2 - 9 } & Females & 2178.00 & 1 & 2178.00 & 4058.00 & 48 & 84.54 & $25.76^{*}$ \\
\hline
\end{tabular}

${ }^{*} p<.01$

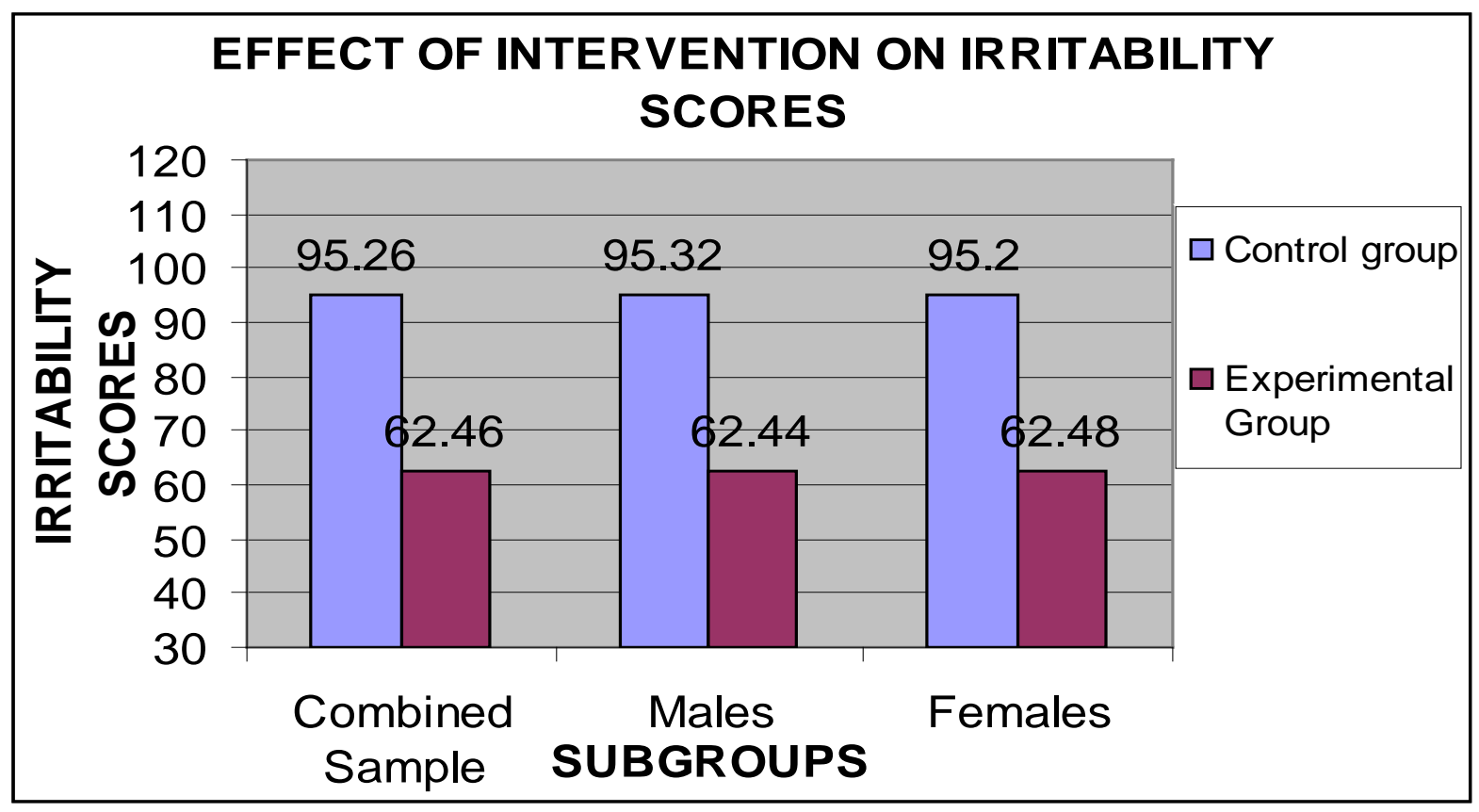

FIGURE I, Means scores of Irritability of males, females and combined sample in both experimental and control group 


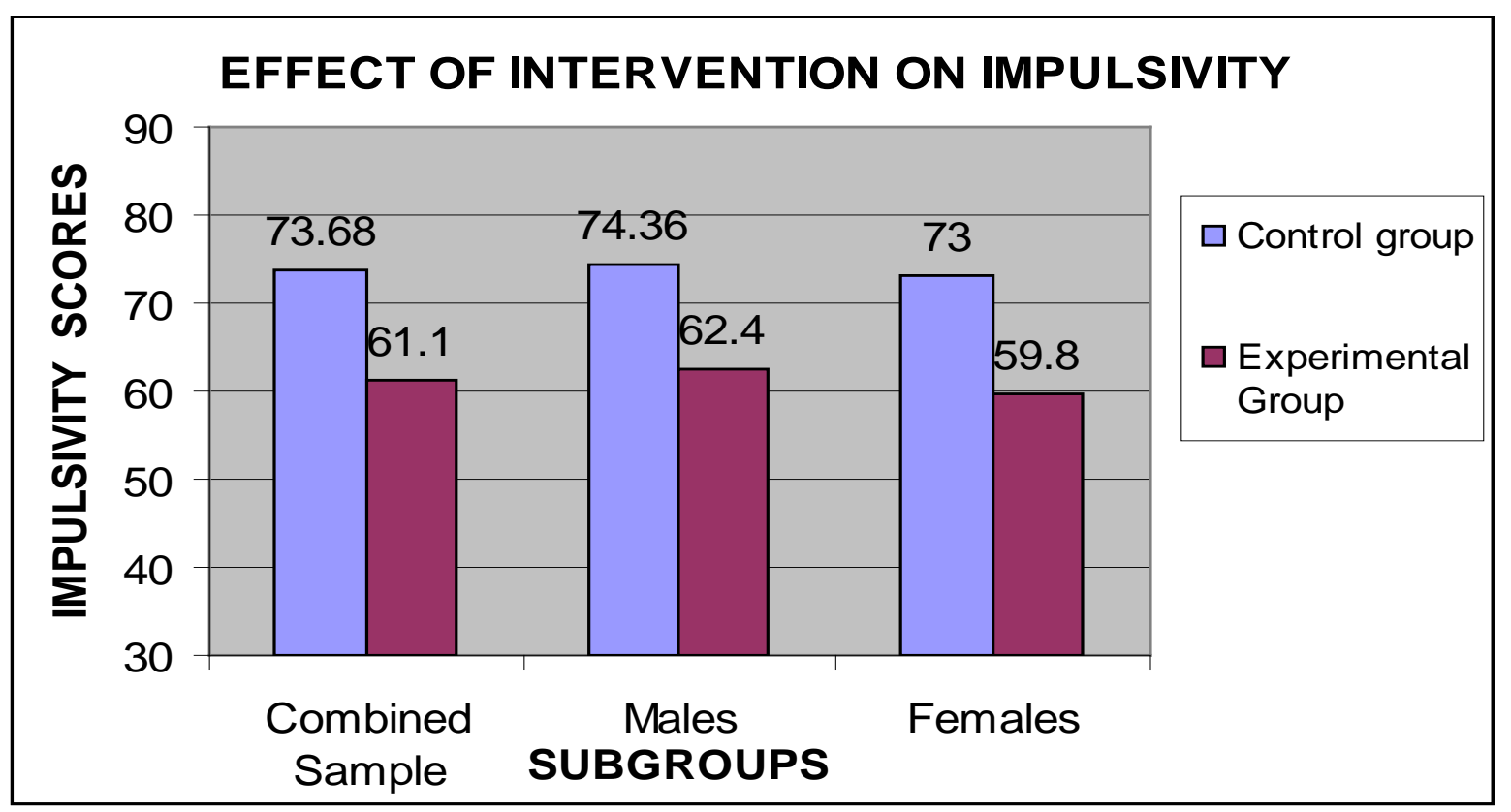

FIGURE II, Means scores of Impulsivity of males, females and combined sample in both experimental and control group

***Analysis of data is carried out with the help of STATISTICA 7 software.

How to cite this article: P Singh (2016) Social Cognitive Intervention: Reducing Irritability and Impulsivity among Aggressive Adolescents, International journal of Indian Psychology, Volume 3, Issue 3, No. 5, DIP: 18.01.078/20160303 